\title{
Comparison of Isocaloric and Hypercaloric Diet in Undernourished Patients
}

\author{
Adnan Barutcu ${ }^{1}$, Saliha Barutcu ${ }^{2}$, Ali Evrim Dogan ${ }^{3}$, Fatih Ozdener ${ }^{4}$, Gokhan Tumgor $^{5}$ and Nurdan Evliyaoglu ${ }^{6}$ \\ ${ }^{1}$ Department of Pediatrics, Sanliurfa Halfeti State Hospital, Sanliurfa, Turkey \\ ${ }^{2}$ Department of Family Medicine, Sanliurfa Halfeti State Hospital, Sanliurfa, Turkey \\ ${ }^{3}$ Department of Medical, Nutricia Advanced Medical Nutrition, Istanbul, Turkey \\ ${ }^{4}$ Department of Pharmacology, Bahcesehir University, School of Medicine, Istanbul, Turkey \\ ${ }^{5}$ Department of Pediatric Gastroenterology, Cukurova University Medical Faculty, Adana, Turkey \\ ${ }^{6}$ Department of Social Pediatrics, Cukurova University Medical Faculty, Adana, Turkey
}

\begin{abstract}
Objective: To determine efficacies of fiber-containing isocaloric and hypercaloric enteral supplements generally used to treat undernutrition.

Study Design: Retrospective cohort study.

Place and Duration of Study: Department of Pediatrics, Sanliurfa Halfeti State Hospital, Turkey from September 2019 to June 2020.

Methodology: Pediatric patients aged 1-19 years were diagnosed solely with primary undernutrition, were given fiber containing isocaloric or hypercaloric enteral supplements for six months based on their energy requirements. A comparative analysis of anthropometrical data was made with each formula. The analysis included baseline weight, height, BMI of patients, and important micro-nutrient levels at three and six months after intervention.

Results: BMI, weight and height z-scores $(p<0.001)$ were improved over six months. There were no differences in BMI and weight scores except for a significant improvement in height between baseline and third month, which was observed in patients who received hypercaloric formula unlike isocolaric formula. There was a two-tailed improvement in blood biochemistry values of both groups.

Conclusion: Both isocaloric and hypercaloric supplementation had positive effects on anthropometry and blood biochemistry. These results show that both formulae are highly beneficial for children with primary undernutrition.
\end{abstract}

Key Words: Pediatrics, Body mass index, Therapeutics, Gastroenterology, Undernutrition.

How to cite this article: Barutcu A, Barutcu S, Dogan AE, Ozdener F, Tumgor G, Evliyaoglu N. Comparison of Isocaloric and Hypercaloric Diet in Undernourished Patients. J Coll Physicians Surg Pak 2022; 32(01):61-67.

\section{INTRODUCTION}

Malnutrition is defined as the disruption of the state of normal nutrition, which includes two ends of nutrition spectrum from undernutrition to overweight. The World Health Organization (WHO) defines malnutrition as the cellular disequilibrium between supplied energy and the energy required for proper growth, maintenance, and function, which is caused by insufficient intake of nutrients, digestive system disruptions, such as malabsorption and metabolic stress, and an increase in thestandard for dietary intake.

Correspondence to: Dr. Adnan Barutcu, Department of Pediatrics, Halfeti State Hospital Siyahgül, Halfeti, Sanliurfa, Turkey

E-mail: adnan_barutcu@hotmail.com

Received: August 15, 2021; Revised: October 20, 2021;

Accepted: November 15, 2021

DOI: https://doi.org/10.29271/jcpsp.2022.01.61
Undernutrition in children causes serious long-term effects that need to be prevented at the possible youngestage, immediately after the signs of underdevelopment, such as susceptibility to infectious diseases due to a weak immune system, poor prognosis in cancer therapy, and delayed wound healing due to the associated disturbed energy metabolism. ${ }^{1}$ Thus, early medical support targeting undernutrition aims to increase the quality of life of patients by developing normal eating behaviour, which in turn, supports normal growth without the signs of undernutrition. In addition to nutritional support for pediatric patients with undernutrition disorder only, immediate nutritional intervention targeting ill children with undernutrition is known to ameliorate disease conditions and reduce the time to recovery. ${ }^{2}$ It has also been reported that the nutritional condition of the patient is an important factor affecting clinical outcome. ${ }^{3}$ Considering the approximately $50 \%$ worldwide prevalence of undernutrition, oral nutritional interventions are common, and must be evaluated objectively. 
According to WHO, undernutrition is diagnosed when an individual's weight-for-age (WFA) z-score is below minus 2 (-2.0) standard deviation (SD). Yet, undernutrition is one of the most prevalent conditions worldwide affecting all age groups. BMI - based on a formula including weight and height - is an important measurement widely used to evaluate nutritional status along with less common measurements, including ideal body weight (IBW) and weight-for-height (WFH). ${ }^{4} \mathrm{BMI}$ is a clinically significantand cost-effective tool for diagnosing undernutrition. ${ }^{5,6}$

The prevalence of undernutrition ranges from $5 \%$ to $50 \%$ in developed countries and developing countries, respectively. ${ }^{7}$ According to globalnutritionreport.org, the prevalence of stunting and wasting conditions of undernutrition in Turkey have been reported as $9.9 \%$ and $1.9 \%$, respectively, which are lower than the average percentages for stunting and wasting reported for developing countries, which are $25 \%$ and $8.9 \%$, respectively. ${ }^{8}$ Moreover, the Turkish Demographic and Health Survey (2013) conducted by Hacettepe University, Institute of Population Studies, Turkey, indicates the importance of undernutrition in Turkey via percentile-based distribution of stunted (low height for age), underweight (low weight for age), wasted (low weight for height), and overweight (high weight for age) children aged $<5$ years. ${ }^{9}$ According to the survey, children aged $<5$ years, $10 \%$ are stunted, $2 \%$ are wasted, $2 \%$ are underweight, and $11 \%$ are overweight/obese. ${ }^{9}$ More than $40 \%$ of children living in Pakistan are stunted, and $17.7 \%$ are wasted. ${ }^{10}$

Undernutrition in children necessitates timely intervention with appropriate support according to specific requirements, because of the susceptibility of developmental mechanisms in children. The type of the nutritional intervention can be different for each patient. The personalised nutritional requirements must, therefore, be identified prior to nutritional intervention. ${ }^{11}$ The long-term and short-term negative effects of disturbed development associated with undernutrition increase greatly as patient age (both adult and children) decreases, which generally results in a poor prognosis or negativeclinical outcome. ${ }^{12}$ The mostimportant effect of undernutrition is on physical growth and cognitive development. Undernutrition negatively affects energy metabolism, which negatively affects the immune system and wound healing, making it difficult to treat some diseases, such as cancer, which require high energy consumption during treatment. ${ }^{13,14}$

Enteral nutritional supplements are widely used to treat children with undernutrition even after the administration of a specialised energy-rich diet. These enteral supplements have a pleasant taste facilitating intake; and vary, depending on the nutritional needs of the patient, as well as patientage and tolerance. $^{15}$ Despite the traditional use of hypercaloric and isocaloric enteral supplements for patients with undernutrition, the number of studies on the effects of these formulas on BMI and micronutrient levels is limited.

The primary objective of the present study was to determine the comparative effects of nutritionally complete fiber-con- taining isocaloric ( $1.0 \mathrm{Kcal} / \mathrm{mL}$ ) and hypercaloric $(1.5 \mathrm{Kcal} / \mathrm{mL})$ enteral supplements administered for a period of six months to treat undernutrition via retrospective analysis.

\section{METHODOLOGY}

This retrospective cohort study included 183 pediatric outpatients aged 1-18 years, who presented with primary undernutrition at Department of Pediatrics, Sanliurfa Halfeti State Hospital, Turkey from September 2019 to June 2020. The criteria for primary undernutrition were assessed by physicians based on a WFA z-score lower than -2 SD, which is consistent with the criteria for undernutrition accepted by WHO, and by exclusion of patients with underlying diseases via retrospective examination of their records. All patients diagnosed with primary undernutrition by physicians based on a WFA z-score lower than -2 SD. Patients with WFA z-scores higher than -2 SD, those under 12 months of age and above 18 years of age, and with infectious and chronic diseases were excluded from the study.

Isocaloric enteral formula was prescribed to $37.7 \%$ (69) of the cohort, while hypercaloric formula was prescribed to $62.3 \%$ (114) of the cohort. All patients were examined with blood immunoglobulins (IGs), and celiac hypothyroid and stool analysis to exclude those with immune system disorders, celiac thyroid disorder, and parasitic diseases. Additionally, patients with acute infection, and patients exposed to tube feeding, were excluded from the study. All patient-records were retrospectively obtained from the hospital record system of Halfeti State Hospital, Sanliurfa, Turkey.

The comparative effects of nutritionally complete MF6-enriched hypercaloric ( $1.5 \mathrm{Kcal} / \mathrm{mL})$ and isocaloric $(1.0 \mathrm{Kcal} / \mathrm{mL})$ enteral supplements were retrospectively investigated with anthropometrical and biochemical measurements in a cohort of 183 undernourished patients aged 1 -19 years for a period of six months. Data was collected by physicians during the first hospital admission and two follow-ups; and retrospectively retrieved during the time of analysis. The difference in overall efficacy between the two enteral supplements was evaluated via extraction of baseline anthropometrical z-scores from the zscores measured at six months of nutritional intervention, and statistically analysed. Due to the steep developmental difference in early ages, the authors of this study divided cohort into 5 sub-groups: ages 1-2 years, 3-5 years, 6-8 years, $9-12$ years and 13-16 years, for visual representation of BMI z-scores. The isocaloric formula $(1.0 \mathrm{Kcal} / \mathrm{mL})$ had $1 \mathrm{Kcal} / \mathrm{mL}$ of energy, $10 \%$ protein, $40 \%$ fat, $47 \%$ carbohydrates, and $3 \%$ dietary fiber, as well as $50 \mathrm{mg}$ of sodium, $104 \mathrm{mg}$ of potassium, and $63 \mathrm{mg}$ of calcium. The hypercaloric formula $(1.5 \mathrm{Kcal} / \mathrm{mL})$ had 1.5 $\mathrm{Kcal} / \mathrm{mL}$ of energy, $9 \%$ protein, $40 \%$ fat, $37.6 \%$ carbohydrates, and $2 \%$ dietary fiber, as well as $64 \mathrm{mg}$ of sodium, $153 \mathrm{mg}$ of potassium, and $84 \mathrm{mg}$ of calcium.

Posology and the type of enteral nutrition was determined according to the Holliday-Segar method by adding $10 \%$ of the total required calories to the amount of energy required by the patient. 
Table I: Demographic data of included and excluded patients.

\begin{tabular}{|c|c|c|c|}
\hline Overall Total & & 215 & \\
\hline Included Patients & & Excluded Patients & \\
\hline Total (N/\%) & $183(100.0)$ & Total (N/\%) & $32(100.0)$ \\
\hline Male (N/\%) & $97(53.0)$ & Male $(\mathrm{N} / \%)$ & $19(59.4)$ \\
\hline Female (N/\%) & $86(47.0)$ & Female (N/\%) & $13(40.6)$ \\
\hline $1.0 \mathrm{kcal} / \mathrm{ml}(\mathrm{N} / \%)$ & $69(37.7)$ & $1.0 \mathrm{kcal} / \mathrm{ml}(\mathrm{N} / \%)$ & $26(81.3)$ \\
\hline $1.5 \mathrm{kcal} / \mathrm{ml}(\mathrm{N} / \%)$ & $114(62.3)$ & $1.5 \mathrm{kcal} / \mathrm{ml}(\mathrm{N} / \%)$ & $6(18.7)$ \\
\hline $\begin{array}{l}\text { Posology, N (Mean energy requirement } \pm \text { SD) } \\
2 \times 1 \\
3 \times 1 \\
4 \times 1\end{array}$ & $\begin{array}{l}107(1147.9 \mathrm{cal} \pm 181.5) \\
71(1626.1 \mathrm{cal} \pm 239.3) \\
5(1822 \mathrm{cal} \pm 53.6)\end{array}$ & $\begin{array}{l}\text { Reason of exclusion } \\
\text { Patient left follow-up (N/\%) } \\
\text { Financial insufficiency (N/\%) } \\
\text { Nausea (N/\%) } \\
\text { Constipation (N/\%) }\end{array}$ & $\begin{array}{l}12(37.5) \\
8(25.0) \\
11(34.4) \\
1(3.1)\end{array}$ \\
\hline $\begin{array}{l}\text { Major admission symptoms (N/\%) } \\
\text { Unable to gain weight [1] } \\
\text { Short stature [2] } \\
\text { Lack of appetite [3] }\end{array}$ & $\begin{array}{l}{[1]: 12(6.6)} \\
{[1+2]: 14(7.7)} \\
{[1+3]: 39(21.3)} \\
{[2+3]: 5(2.7)} \\
{[1+2+3]: 113(61.8)}\end{array}$ & & \\
\hline
\end{tabular}

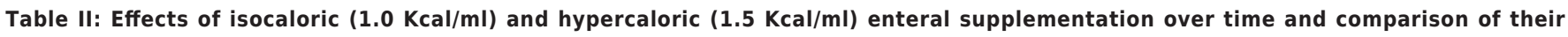
overall efficacy.

\begin{tabular}{|c|c|c|c|}
\hline Type of Intervention & $\begin{array}{l}\text { Mean Body } \\
\text { Weight Increase }\end{array}$ & $\begin{array}{l}\text { Mean Body } \\
\text { Height Increase }\end{array}$ & $\begin{array}{l}\text { Mean BMI Z-score } \\
\text { Improvement }\end{array}$ \\
\hline $1.0 \mathrm{kcal} / \mathrm{ml}$ & $-1.90 \pm 0.48 *$ & $-2.02 \pm 1.07 *$ & $-1.29 \pm 1.08 *$ \\
\hline$n=69$ & $-1.62 \pm 0.54 \dagger$ & $-2.00 \pm 1.01 \dagger$ & $-0.89 \pm 0.99 \dagger$ \\
\hline$($ Mean $\pm S D)$ & $-1.32 \pm 0.53 \ddagger$ & $-1.72 \pm 0.98 \ddagger$ & $-0.72 \pm 0.97 \ddagger$ \\
\hline Overall improvement & $<0.001 \|$ & $<0.001 \|$ & $<0.001 \S$ \\
\hline Baseline vs. third month & $<0.001$ & 1.000 & $<0.001 \S$ \\
\hline Third month vs. sixth month & $<0.001$ & $<0.001$ & $0.006 \S$ \\
\hline Baseline vs. sixth month & $<0.001 \|$ & $<0.001 \|$ & $<0.001 \S$ \\
\hline $1.5 \mathrm{kcal} / \mathrm{ml}$ & $-2.01 \pm 0.39 *$ & $-2.45 \pm 1.04 *$ & $-1.45 \pm 0.98 *$ \\
\hline $\mathrm{n}=114$ & $-1.74 \pm 0.43 \dagger$ & $-2.30 \pm 1.02 \dagger$ & $-1.02 \pm 1.00 \dagger$ \\
\hline$($ Mean \pm SD) & $-1.53 \pm 0.46 \ddagger$ & $-2.09 \pm 1.01 \ddagger$ & $-0.82 \pm 0.89 \ddagger$ \\
\hline Overall improvement & $<0.001 \|$ & $<0.001 \|$ & $<0.001 \S$ \\
\hline Baseline vs. third month & $<0.001 \|$ & $<0.001 \|$ & $<0.001 \S$ \\
\hline Third month vs. sixth month & $<0.001 \|$ & $<0.001 \|$ & $<0.001 \S$ \\
\hline Baseline vs. sixth month & $<0.001 \|$ & $<0.001 \|$ & $<0.001 \S$ \\
\hline & $0.122+\dagger$ & $0.456+\dagger$ & $0.332 * *$ \\
\hline 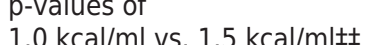 & $0.58 \pm 0.43$ & $0.30 \pm 0.51$ & $0.57 \pm 0.71$ \\
\hline $\begin{array}{l}1.0 \mathrm{kcal} / \mathrm{ml} \mathrm{vs} .1 .5 \mathrm{Kcal} / \mathrm{ml} \neq \\
\text { (Mean difference } \pm S D \text { ) }\end{array}$ & $0.48 \pm 0.30$ & $0.35 \pm 0.40$ & $0.64 \pm 0.70$ \\
\hline \multicolumn{4}{|c|}{$\begin{array}{l}n, \text { Number of patients BMI, Body mass index } S D \text {, Standard deviation*, Baseline } t \text {, Third Month } \neq \text {, Sixth Month } \S \text {, Friedman test } \|, \text { Repeated measures ANOVA } * * \\
\text { Student's } t \text {-test }+t, \text { Mann-Whitney } U \text { test } \neq \# Z \text {-score differences between baseline and sixth month were utilized to compare overall efficacy of } 1.0 \mathrm{kcal} / \mathrm{ml} \text { and } \\
1.5 \mathrm{kcal} / \mathrm{ml} \text { supplements. Mean difference } \pm S D \text { values were given respectively in the order of } 1,0 \mathrm{kcal} / \mathrm{ml} \text { and } 1.5 \mathrm{kcal} / \mathrm{ml} \text {. Significant results were indicated in } \\
\text { bold. }\end{array}$} \\
\hline
\end{tabular}

Moreover, only $50 \%$ of the required energy was supported by enteral nutrition, while the remaining $50 \%$ was left as the preferred diet of the patient. Fifty percent of energy requirement of all patients were nutritionally supported, according to above-mentioned calculation with nutritionally complete MF6 fiber-containing isocaloric $(1.0 \mathrm{Kcal} / \mathrm{mL})$ and hyper-caloric $(1.5 \mathrm{Kcal} / \mathrm{mL})$ enteral formulae. No dietary intervention or suggestion was made for the remaining $50 \%$ of the energy requirement.

Three-layer retrospective analysis was performed for six months of regular use of the enteral supplements, including baseline anthropometrical and biochemical measurements prior to the nutritional intervention, with repeat measurements after three and six months of enteral supplementation. The measurements included BMI z-scores, weight z- scores, and height z-scores, as well as hemoglobin (HGB), hematocrit percentage (HCT), iron, ferritin, B12, and 25-hydroxyvitamin D3 (25D3) levels to evaluate the effects of the nutritional intervention.

$\mathrm{BMI}$ values were standardised, according to the age-based values of Box-Cox transformation for skewness (L), median (M), and generalised coefficient of variation (S) parameters.

The BMI z-score was calculated, according to the following formula:

$B M I Z=\left[\left(\frac{B M I}{M}\right)^{L}-1\right] \div(L \times S)$

Height and weight values were standardised, according to the reference population indicated in an extensive study limited to Turkish children. ${ }^{16}$ 


\section{A) BMI Z-scores during 6 months according to developmental age groups}

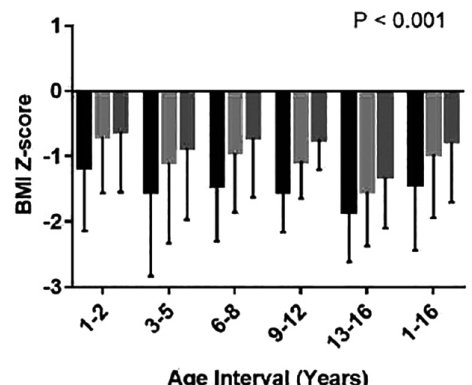

BMI (0) Z-score (Initial)

BMI (0) Z-score (3 Months)

BMI (0) Z-score (6 Months)

C) Hematocrit percentage during 6 months

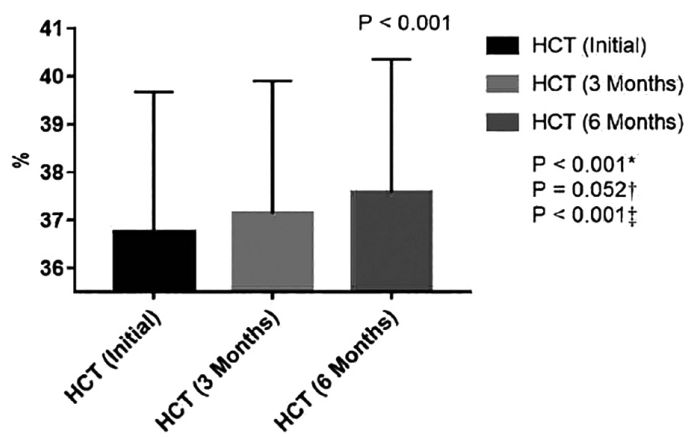

E) 25-Hydroxyvitamin D3 concentration during 6 months

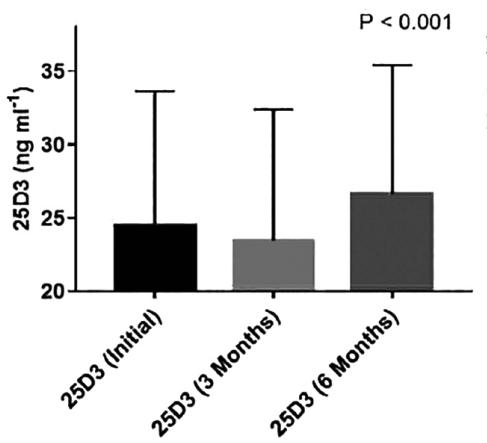

\section{B) Hemoglobin concentration during 6 months}

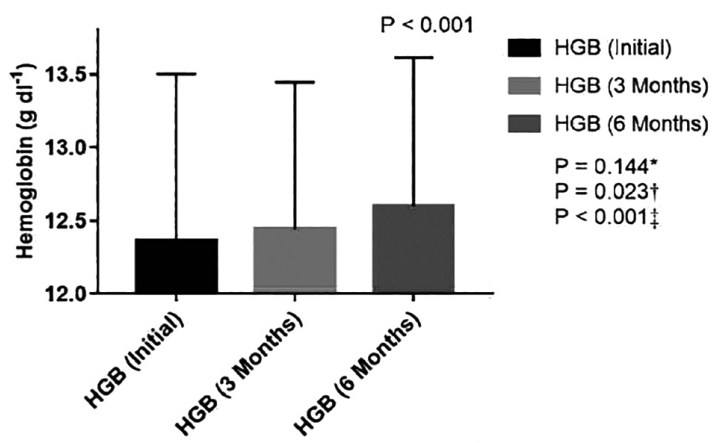

D) Iron concentration during 6 months

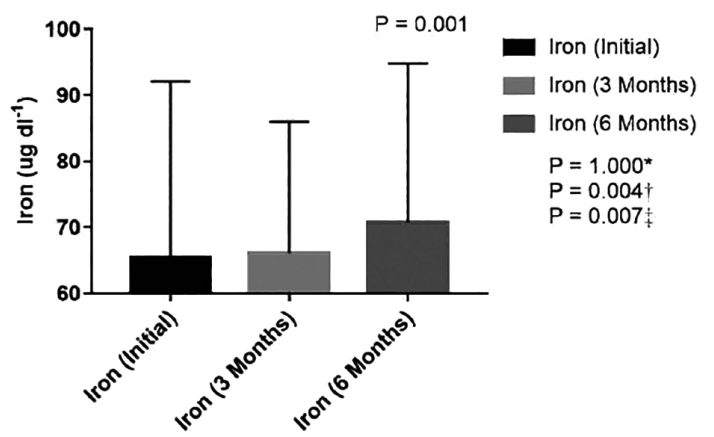

F) Ferritin concentration during 6 months

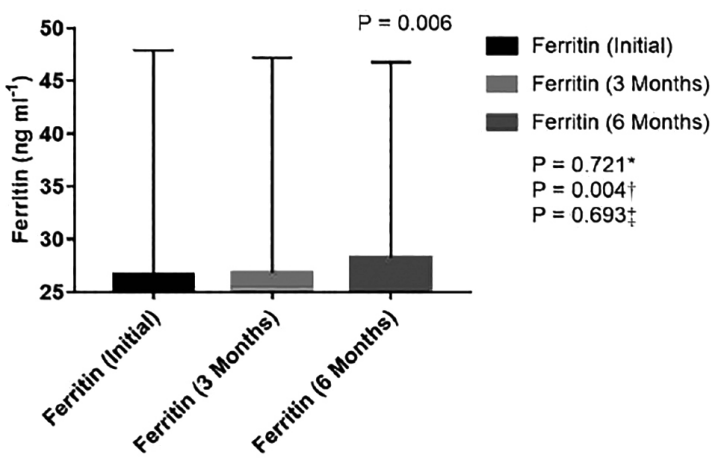

G) B12 concentration during 6 months

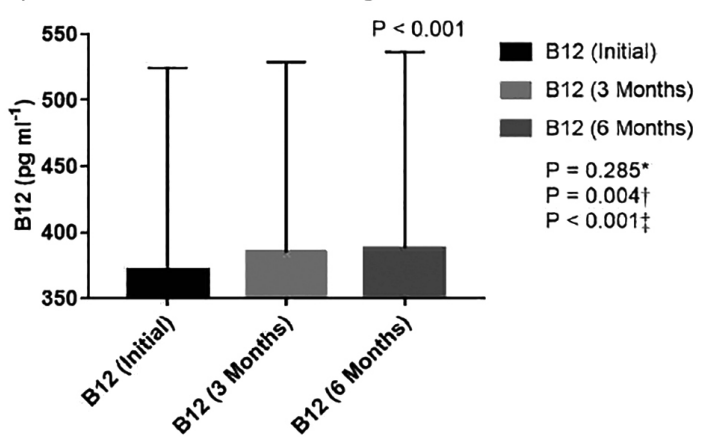

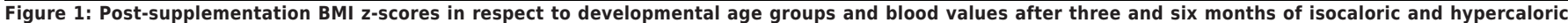

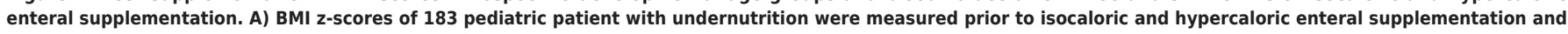

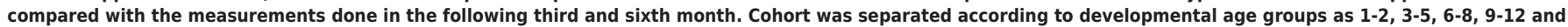

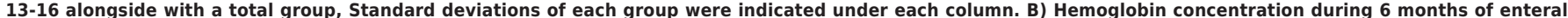

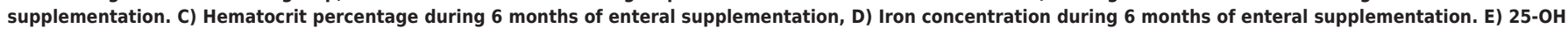

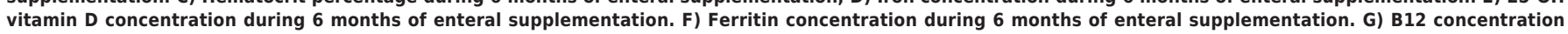
during 6 months of enteral supplementation.

*: Baseline vs. 3rd month; †: 3rd Month vs. 6th month; ¥: Baseline vs. 6th month. 
Statistical analysis was performed using IBM SPSS Statistics for Windows version 20.0 (IBM Corp., Armonk, NY, US). Normality was checked with the Shapiro-Wilk test and a $p$ value $<0.05$ was considered non-parametric distribution and a $p>0.049$ was considered parametric distribution. Related histograms were also checked to confirm the test result. Friedman's test was used in the case of non-parametric data, followed by the Wilcoxon test to compare each group. For parametric data, the repeated measures ANOVA was utilised, followed by Wilks' lambda as the multivariate test. Bonferroni correction with a significance of $p<0.05$ was utilised during the analysis of pairwise significance of each measurement in the case of repeated measures ANOVA analysis. The Mann-Whitney U-test and student's t-test were used to compare z-score improvements between the isocaloric $(1.0 \mathrm{Kcal} / \mathrm{mL})$ and hypercaloric $(1.5 \mathrm{Kcal} / \mathrm{mL})$ subgroups for non-parametrically and parametrically distributed data. The level of statistical significance was set at $p<0.05$.

\section{RESULTS}

This study included 183 pediatric outpatients ( $n=97,53.0 \%$ boys and $86,47.0 \%$ girls) aged 1-18 (5.5 \pm 3.84 ) years, who presented with primary undernutrition. Most frequent major admission symptom was inability to gain weight, followed by anorexia with $85.8 \%(n=157)$ and short stature with $71.6 \%$ $(n=131)$. In total, $97.4 \%(n=178)$ of the 183 patients with primary undernutrition were unable to gain weight and the remaining $2.6 \%(n=5)$ had short stature and anorexia. Moreover, $61.8 \%(n=113)$ of the patients were unable to gain weight, had short stature and anorexia, simultaneously. Demographic data of the cohort are presented in Table I.

As compared to baseline BMI z-scores, measurements after three and six months of enteral supplementation were significantly lower $(p<0.001$, Figure $1 A)$. In addition, the developmental age sub-groups in Figure $1 \mathrm{~A}$ also showed a similar trend of improvement. Both isocaloric and hypercaloric supplements significantly improved weight, height and BMI $z$-scores over a period of six months $(p<0.001$ for weight, height and BMI z-scores, Table II). Moreover, no significant difference was observed between overall efficacies of the two enteral supplements as the pairwise analysis or each follow-up showed significant improvements $(p=0.006$ for third month vs. sixth month improvement of BMI z-score in the patients prescribed with $1.0 \mathrm{Kcal} / \mathrm{ml}$ formula and $p<$ 0.001 for all baseline vs. third month, third month vs. sixth month and baseline vs. sixth month improvements of weight, height and BMI z-scores in the patients prescribed with either $1.0 \mathrm{Kcal} / \mathrm{ml}$ or $1.5 \mathrm{Kcal} / \mathrm{ml}$ formula), except for the lack of improvement observed between baseline and third month height z-scores in case that patients received isocaloric supplements $(p=1.000)$. In contrast, patients given hypercaloric supplement showed steady improvement at each follow-up (Table II).
Wilks' lambda values for HGB (0.915), HCT percentage (0.864), and iron (0.935) concentrations indicated that they were only slightly affected by the nutritional intervention $(p<0.001, p<0.001$ and $p=0.006$, respectively, Figure 1B-D). For 25D3, the main difference was observed after 3 months $(p<0.001)$ (Figure 1E). Ferritin and B12 values increased significantly over the course of 6 months $(p=0.001$ and $\mathrm{p}<0.001$, respectively, Figure $1 \mathrm{~F}$ and $1 \mathrm{G}$ ).

\section{DISCUSSION}

Undernutrition is a serious and common disorder affecting $5 \%$ to $50 \%$ of the world's population in developing and developed countries, respectively. This is a unique study referring the differences between multi fiber containing isocaloric (1.0 $\mathrm{Kcal} / \mathrm{mL}$ ) and hypercaloric ( $1.5 \mathrm{Kcal} / \mathrm{mL})$ enteral formulas in terms of BMI, weight and height z-scores of pediatric patients with primary undernutrition in Turkey. However, the database on the daily calorie intake of the patients was lacking during the enteral intervention. It is crucial to create a comprehensive database on the efficacies and compatibilities of different enteral formulas to be able to select the appropriate nutritional intervention and prevent food insecurity. Moreover, among the causes of undernutrition in Turkey, food insecurity has been reported to be an another important factor. ${ }^{17}$ There is a need for large-cohort studies with relevant subjects of nutritional intervention and food insecurity from different regions of Turkey.

There was a significant convergence of the BMI z-scores to zero during the 6-month enteral supplementation period (Figure $1 \mathrm{~A})$. The isocaloric $(1.0 \mathrm{Kcal} / \mathrm{mL})$ and hypercaloric $(1.5$ $\mathrm{Kcal} / \mathrm{mL}$ ) formulas similarly improved the BMI Z-scores over the six months of administration, which indicates that both formulas are clinically beneficial as a nutritional intervention (Table II). Longer intervention may be required for patients with < -2 SD of BMI after six months of intervention. It has been known that fiber containing calorie-rich pediatric enteral formulas are useful for undernourished children with normal gastrointestinal functions. ${ }^{18}$ Fiber containing diets decrease the risk of diarrhea. ${ }^{19}$

Weight and height z-scores were also significantly improved during the 6-month enteral nutritional supplementation (Table II). However, unlike the isocaloric formula, the hypercaloric formula showed significant height gain in the pairwise analysis of baseline and $3^{\text {rd }}$ month height $z$-scores even though no significant difference was observed in terms of overall efficacy (Table II). Despite the similarity of overall efficacy between the two enteral formulas, which is in line with the study conducted by Devaera et al., which shows the superiority of hypercaloric formula in pairwise analysis of baseline versus third month height $z$-scores differs from the results of that study. ${ }^{15}$ This result, however, may be due to the longer follow-up period of three months in this study, compared with four weeks in the referred study. Finally, there was a two-tailed improvement $(p<0.000)$ in HGB, HCT, iron, 25D3, ferritin, and B12 values (Figure 1B-G). 
Main limitation of the study is the retrospective design of the study and the inclusion of an outpatient cohort. This precluded the gathering of patient dietary data outside the hospital.

Despite worldwide use of enteral supplements for undernutrition, which negatively affects the general health condition, the number of studies comparing efficacies of different nutrients is limited. This is the main importance of the present results.

\section{CONCLUSION}

Both the isocaloric and hypercaloric enteral supplements yielded significant improvements in $\mathrm{BMI}$, and weight and height z-scores during the 6-month administration with no significant difference in terms of overall efficacy. However, the hyper-caloric formula showed a greater improvement in height z-scores between baseline and 3-month follow-up compared to isocaloric formula, which showed insignificant improvement between baseline and third month. There was a 2-tailed improvement in blood biochemistry values as the number of patients with high/low baseline blood values decreased over time, which steadily increased over threshold during intervention.

\section{ETHICAL APPROVAL:}

The ethical approval for the study was obtained from the Ethics Committee of University Faculty of Medicine on 05/08/2019, session No. 09, in accordance with the principles of the Helsinki Declaration. Moreover, the study protocol received Institutional Review Board approval from Sanliurfa Halfeti State Hospital on 10.7.2019, No. 17637724-619.

\section{PATIENTS' CONSENT:}

All participants provided informed consent in the format required by the relevant authorities and/or boards.

\section{CONFLICT OF INTEREST:}

The authors declared no conflict of interest.

\section{AUTHORS' CONTRIBUTION:}

$A B, S B, F O$ : Data acquisition and analysis, interpretation, drafting, final approval. Conception and design, Interpretation, critical revision, final approval.

AED: Analysis and interpretation, drafting, final approval. GT, NE: Interpretation, critical Revision, final approval.

\section{REFERENCES}

1. Barr RD, Stevens MCG. The influence of nutrition on clinical outcomes in children with cancer. Pediatr Blood Cancer 2020; 67(S3):e28117. doi.org/10.1002/pbc.28117.

2. Wischmeyer PE. Tailoring nutrition therapy to illness and recovery. Crit Care 2017; 21(Suppl 3):316-doi: 10.1186/s13054-017-1906-8.

3. Raju U, Choudhary S, Harjai MM. Nutritional support. In the critically III child. Med J Armed Forces India 2005; 61(1): 45-50. doi.10.1016/S0377-1237(05)80119-4.
4. Brinksma A, Huizinga G, Sulkers E, Kamps W, Roodbol P, Tissing W. Malnutrition in childhood cancer patients: A review on its prevalence and possible causes. Crit Rev Oncol Hematol 2012; 83(2):249-75 doi: 10.1016/j.critrevonc.2011.12.003.

5. Ortega FB, Sui X, Lavie CJ, Blair SN. Body mass index, the most widely used but also widely criticized index: Would a Criterion standard measure of total body fat be a better predictor of cardiovascular disease mortality? Mayo Clin Proc 2016; 91(4):443-55. doi: 10.1016/j.mayocp. 2016.01.008.

6. Hall DMB, Cole TJ. What use is the BMI? Arch Dis Child 2006; 91(4):283-6. doi: 10.1136/adc.2005.077339.

7. Sahin Y, Goktepe AR, Ozen E. Prevalence of malnutrition in a tertiary hospital in Turkey: Overlooked subject? Arch Clin Gastroenterol 2017; 3:041-6. doi: $10.17352 / 2455-2283.000037$.

8. Country overview, Malnutrition burden, 2013 [17 August 2020 ]. Available from: http://globalnutritionreport.org/resources/nutrition-profiles/a sia/western-asia/turkey/.

9. Studies HUloP. 2013 Turkey demographic and health survey. Hacettepe University Institute of Population Studies, TR Ministry of Health; 2014. p. 164-8.

10. Government of Pakistan MoNHS, Regulations and Coordination. National Nutrition Survey. In: Wing N, editor. 2018.

11. Yi DY. Enteral nutrition in pediatric patients. Pediatr Gastroenterol Hepatol Nutr 2018; 21(1):12-9 doi: 10.5223/ pghn.2018.21.1.12.

12. Bundy DAP, de Silva N, Horton S, Patton GC, Schultz L, Jamison DT. Investment in child and adolescent health and development: Key messages from disease control priorities, 3rd edition. Lancet (London, England) 2018; 391 (10121):687-99.doi: 10.1016/s0140-6736(17)32417-0.

13. Weijs PJM, Mogensen KM, Rawn JD, Christopher KB. Protein Intake, nutritional status and outcomes in ICU survivors: A Single Center Cohort Study. J Clin Med 2019; 8(1):43. doi: 10.3390/jcm8010043.

14. Salciute-Simene E, Stasiunaitis R, Ambrasas E, Tutkus J, Milkevicius I, Sostakaite G, et al. Impact of enteral nutrition interruptions on underfeeding in intensive care unit. Clin Nutr 2021; 40(3):1310-7. doi.org/10.1016/j.clnu.2020. 08.014.

15. Devaera Y, Syaharutsa DM, Jatmiko HK, Sjarif DR. Comparing compliance and efficacy of isocaloric oral nutritional supplementation using $1.5 \mathrm{Kcal} / \mathrm{mL}$ or $1 \mathrm{Kcal} / \mathrm{mL}$ sip feeds in mildly to moderately malnourished indonesian children: A randomised controlled trial. Pediatr Gastroenterol Hepatol Nutr 2018; 21(4):315-20. doi: 10.5223/pghn.2018.21.4.315.

16. Neyzi O, Günöz H, Furman A, Bundak R, Gokcay G. Reference values for body weight, height, head circumference and body mass index in Turkish children. J Child Health Dise 2008; 51(1):1-14.

17. Hakan Bucak I, Tumgor G, Temiz F, Afat E, Yasemen Canöz $P$, Turgut $M$. Food insecurity: Experience in a tertiary health center in Turkey. Minerva Pediatr 2015; 67(2):117-21.

18. Kansu A, Durmaz Ugurcan O, Arslan D, Unalp A, Celtik C, 
Sarıoglu AA. High-fibre enteral feeding results in improved anthropometrics and favourable gastrointestinal tolerance in malnourished children with growth failure. Acta Paediatr 2018; 107(6):1036-42. doi: 10.1111/apa.14240.
19. Kamarul Zaman M, Chin K-F, Rai V, Majid HA. Fiber and prebiotic supplementation in enteral nutrition: A systematic review and meta-analysis. World J Gastroenterol 2015; 21(17):5372-81. doi: 10.3748/wjg.v21.i17.5372. 